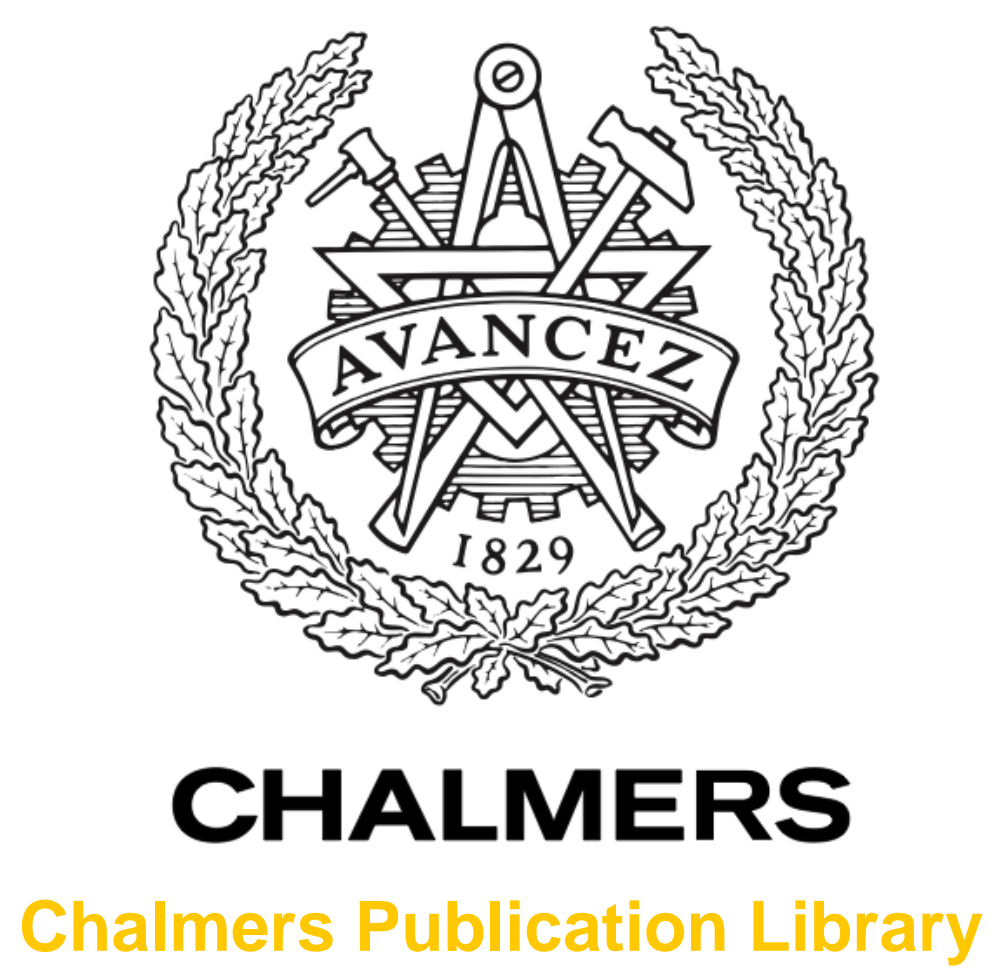

Backscatter signatures of wind-thrown forest in satellite SAR images

This document has been downloaded from Chalmers Publication Library (CPL). It is the author's version of a work that was accepted for publication in:

Proceedings of IEEE International Geoscience and Remote Sensing Symposium (IGARSS), 22-27 July 2012, Munich, Germany (ISSN: 2153-6996)

Citation for the published paper:

Eriksson, L. ; Fransson, J. ; Soja, M. (2012) "Backscatter signatures of wind-thrown forest in satellite SAR images". Proceedings of IEEE International Geoscience and Remote Sensing Symposium (IGARSS), 22-27 July 2012, Munich, Germany pp. 6435-6438.

http://dx.doi.org/10.1109/IGARSS.2012.6352732

Downloaded from: http://publications.lib.chalmers.se/publication/172219

Notice: Changes introduced as a result of publishing processes such as copy-editing and formatting may not be reflected in this document. For a definitive version of this work, please refer to the published source. Please note that access to the published version might require a subscription.

Chalmers Publication Library (CPL) offers the possibility of retrieving research publications produced at Chalmers University of Technology. It covers all types of publications: articles, dissertations, licentiate theses, masters theses, conference papers, reports etc. Since 2006 it is the official tool for Chalmers official publication statistics. To ensure that Chalmers research results are disseminated as widely as possible, an Open Access Policy has been adopted.

The CPL service is administrated and maintained by Chalmers Library. 


\title{
BACKSCATTER SIGNATURES OF WIND-THROWN FOREST IN SATELLITE SAR IMAGES
}

\author{
Leif E. B. Eriksson ${ }^{1}$, Johan E. S. Fransson ${ }^{2}$, Maciej J. Soja ${ }^{1}$ and Maurizio Santoro ${ }^{3}$ \\ ${ }^{1}$ Chalmers University of Technology, Dept. of Earth and Space Sciences, Gothenburg, Sweden \\ ${ }^{2}$ Swedish University of Agricultural Sciences, Dept. of Forest Resource Management, Umeå, Sweden \\ ${ }^{3}$ Gamma Remote Sensing, Gümligen, Switzerland
}

\begin{abstract}
Two field experiments have been conducted in Sweden to allow an evaluation of the backscatter signatures of windthrown forest from L-band, C-band and X-band Synthetic Aperture Radar. When the trees are felled the backscattered signal from TerraSAR-X (X-band) increase with about 1.5 $\mathrm{dB}$, while for ALOS PALSAR (L-band) a decrease with the same amount is observed. Radar images with fine spatial resolution also show shadowing effects that should be possible to use for identification of storm felled forest.
\end{abstract}

Index Terms - Synthetic Aperture Radar, forestry, wind-throw, storm damage, clear-cut

\section{INTRODUCTION}

In 2005 and 2007 devastating storms hit Sweden (among other countries) causing large damages to forested areas. In these two storms, it was estimated that about 70 million cubic meters (2005) and about 12 million cubic meters (2007) of timber fell down to a value of billions of Euro. At occasions like these, rapid mapping of wind-thrown forests is crucial in order to salvage timber values and prevent insect outbursts that could kill the remaining standing trees. After a severe storm it is also of high importance to get a fast overview to assess the roads that should be cleared from wind-thrown trees as well as to detect power lines that are broken.

After the storm in 2005, research activities for detection of wind-thrown forest were initiated and conducted in Sweden. A large number of different spaceborne remote sensing techniques were investigated. The success of the optical satellites was limited by the prevailing winter conditions (low sun-angle, extensive cloud-cover and variable snow cover). The analysis of a limited number of backscatter intensity images from C-band Synthetic Aperture Radar (SAR) indicated that at this frequency it was not possible to detect wind-thrown forests except in the highest resolution Radarsat-1 images, where changes in texture related to changes in shadowing from standing/fallen trees were observed [1].

To further explore the feasibility of mapping windthrown forest with radar remote sensing, two controlled experiments were conducted where trees were felled manually to simulate wind-thrown forest [2], [3]. The experiments took place in 2006 and 2009 at the test site Remningstorp located in the south of Sweden. During both experiments, data from the Advanced Land Observing Satellite (ALOS) Phased Array type L-band Synthetic Aperture Radar (PALSAR) were acquired and in 2009 SAR data with high spatial resolution was also acquired with Radarsat-2 and TerraSAR-X.

\section{MATERIAL AND METHOD}

The simulation of wind-thrown forest was done by manual felling of trees in two directions to simulate two possible main wind directions during a storm. In both 2006 and 2009 four coniferous stands, each with a size of about 1.0 to 1.2 ha, were felled and the trees were left for a few orbit repeat cycles to ensure image acquisitions after the "storm". The felled trees were then harvested and removed and the areas could be used for analysis of signatures from clear-cuts. The locations of the test areas and reference areas during the two campaigns are shown in Fig. 1. ALOS PALSAR data were acquired according to JAXA's global observation strategy for ALOS, i.e. at $34.3^{\circ}$ look angle in ascending passes with Fine Beam Single (FBS) polarization $(\mathrm{HH})$ mode during the winter and Fine Beam Dual (FBS) polarization $(\mathrm{HH}+\mathrm{HV})$ mode during the summer and autumn. Radarsat-2 and TerraSAR-X were programmed to acquire data at different look angles and in both ascending and descending passes to study differences in the shadowing effects. From each satellite about 20 images have been analyzed. 


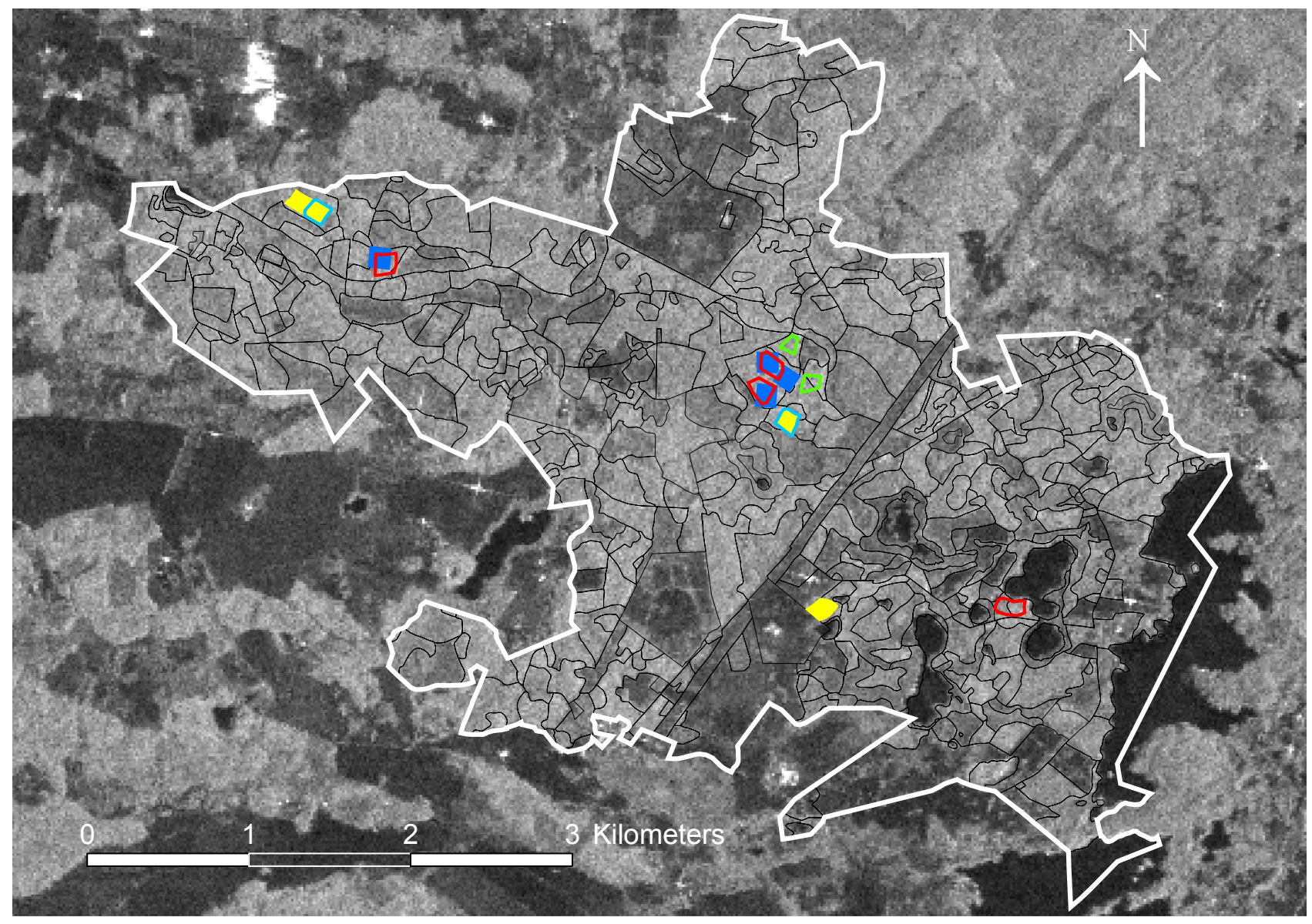

Figure 1. Remningstorp test site (white boundary) showing 4 stands in yellow and 4 stands in blue subject to treatments in 2006 and 2009 , respectively (artificially wind-thrown and clear-felled forest), 4 forest reference stands with red boundaries in 2006, 2 forest reference stands with green boundaries in 2009, 2 clear-felled reference stands with light blue boundaries in 2009, and stand delineations (black boundaries) overlayed on the average backscatter intensity from two PALSAR FBS (look angle $34.3^{\circ}$, HH-polarization) images acquired on 2006-09-08 and 2006-10-07, displayed with a pixel spacing of 15 m (C JAXA/METI 2006).

\section{RESULTS}

The results from 2006 show that, compared to selected reference forest stands, the backscatter intensity from the ALOS PALSAR FBS HH polarized images decreases about $1.5 \mathrm{~dB}$ when the trees are felled (Fig. 2). The same decrease is observed for HH-polarized ALOS PALSAR FBD images in 2009 (Fig. 3). TerraSAR-X HH-polarized backscatter show a significant increase when the trees were felled and the difference to selected reference forest stands is about 1.5 $\mathrm{dB}$ (Fig. 4). The corresponding differences for Radarsat-2 are $0.2 \mathrm{~dB}$ to $1.2 \mathrm{~dB}$ for HH-polarization. Shadowing effects in fine resolution TerraSAR-X data show a potential for detection of wind-throw with separation to the reference forest backscatter of around $8 \mathrm{~dB}$ (Figs. 5 and 6). These figures also indicate that the variation in incidence angle that is given by different orbit tracks only have a marginal effect on the backscatter values. The deviation from the trend that can be observed during the clear-cut phase for track 2 in Fig. 4 is most likely due to rain fall. In general, the temporal effects caused by precipitation seem to have a higher influence on the backscatter values than the difference in incidence angles. Similar results are seen for the high- resolution data from Radarsat-2. More results, including also HV-polarized data from Radarsat-2 and ALOS PALSAR, are presented in [4].

\section{DISCUSSION AND CONCLUSIONS}

The experiments indicate that it should be possible to detect wind-thrown forest with high-resolution spaceborne SAR. When trees are felled, the changes in backscatter level for areas without shadowing effects are small and several images might be required to increase the reliability of the detections. The backscatter changes are stronger for areas where new shadows occur (or disappear) after a storm, but a 
spatial resolution finer than about $10 \mathrm{~m}$ is required. After a real storm the shadowing effects will in many cases be more diffuse than from the rectangular areas that were used in the experiments that are presented in this paper, which will increase the requirements on the resolution. It should also be pointed out that when a tree is felled by strong wind it is either uprooted or the stem breaks. The uprooted root system is often several meters in diameter and cause additional roughness and scattering surfaces that has not been possible to simulate in the experiment described in this paper. This difference between the conducted experiment and real con-ditions is expected to have a larger effect on the backscatter for longer wavelengths and might introduce double bounce scattering if the trees are felled in the same direction as the look direction of the SAR.

\section{ACKNOWLEDGMENT}

This work was financially supported by the Swedish National Space Board and the Hildur and Sven Wingquist's Foundation for Forest Research. ALOS PALSAR data have been provided by JAXA EORC within the framework of the JAXA Kyoto \& Carbon Initiative. Data from Radarsat-2 were granted within the Canadian program for Science and Operational Applications Research for Radarsat-2 (SOAR), project number 3931 and data from TerraSAR-X were provided by the German Aerospace Center (DLR) under the agreement for proposal LAN0126. Meteorological observations from Remningstorp were available through a license agreement with SMHI. A. Pantze is acknowledged for his contribution to the planning of the storm simulation in 2009.

\section{REFERENCES}

[1] L.M.H. Ulander, G. Smith, L. Eriksson, K. Folkesson, J.E.S. Fransson, A. Gustavsson, B. Hallberg, S. Joyce, M. Magnusson, H. Olsson, A. Persson, and F. Walter, "Mapping of wind-thrown forests in southern Sweden using space- and airborne SAR," in Proc. IGARSS 2005, Seoul, Korea, 25-29 July, 2005, pp. 36193622.

[2] J.E.S. Fransson, M. Magnusson, H. Olsson, L.E.B. Eriksson, G. Sandberg, G. Smith-Jonforsen, and L.M.H. Ulander, "Detection of forest changes using ALOS PALSAR satellite images," in Proc. IGARSS 2007, Barcelona, Spain, 23-27 July, 2007, pp. 2330-2333.

[3] J.E.S. Fransson, A. Pantze, L.E.B. Eriksson, M.J. Soja, and M. Santoro, "Mapping of wind-thrown forests using satellite SAR images", in Proc. IGARSS 2010, Hawaii, USA, 25-30 July, 2010, pp. $1242-1245$.

[4] L.E.B. Eriksson, J.E.S. Fransson, M.J. Soja, and M. Santoro, "Spaceborne SAR for detection of boreal wind-thrown forest and clear-cuts", Remote Sensing of Environment, submitted.

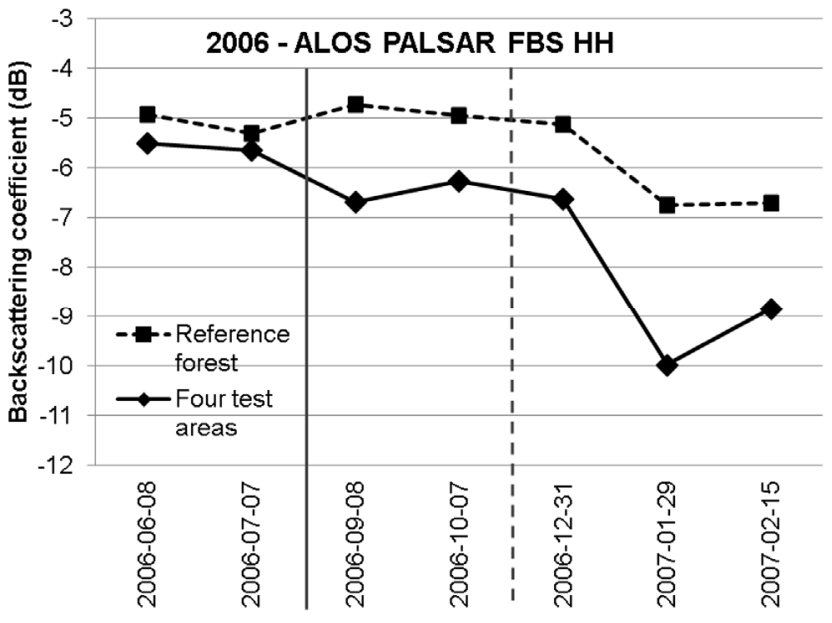

Figure 2. Time series of ALOS PALSAR backscatter values from 2006. Includes images from both ascending and descending passes.

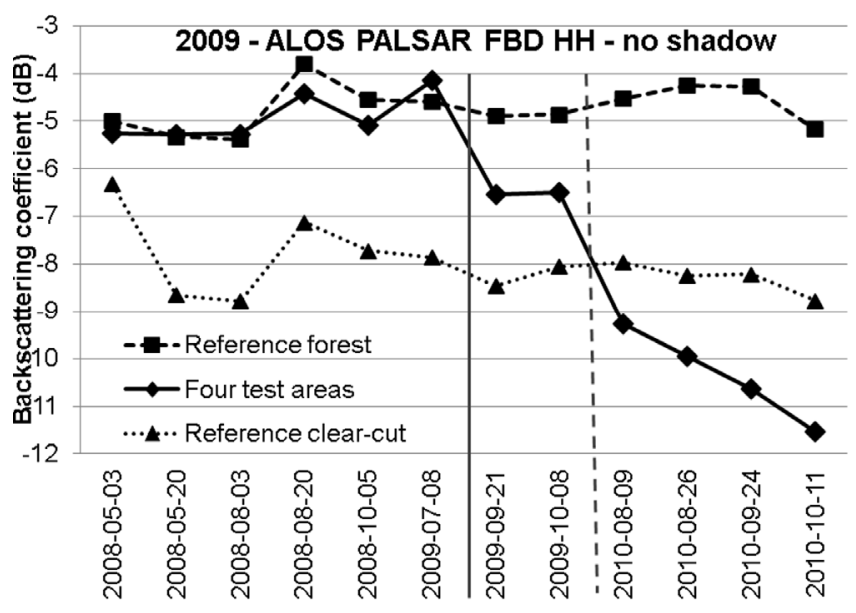

Figure 3. Time series of ALOS PALSAR backscatter values from 2009. Areas with shadow or layover have been excluded. Includes images from both ascending and descending passes.

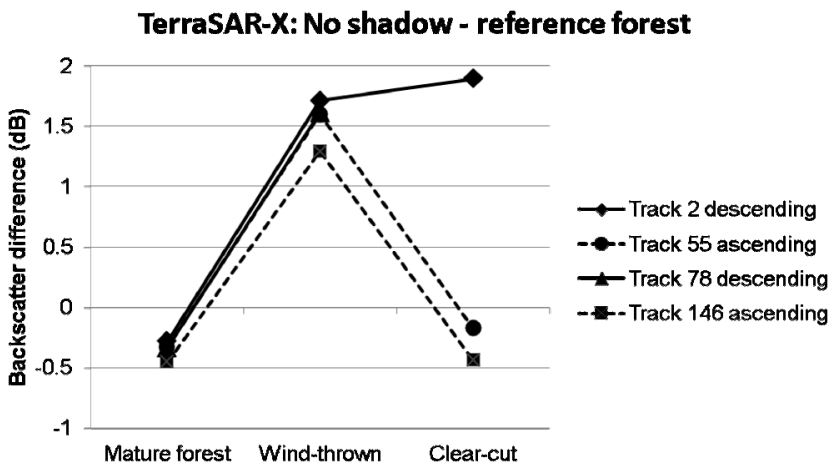

Figure 4. Difference in TerraSAR-X backscatter values $(\mathrm{HH})$ between treated test areas and reference stands. Areas with shadow or layover have been excluded. Includes images from both ascending and descending satellite passes. Each point represents an average of all data collected during each treatment phase. 
TerraSAR-X:Ascending shadow - reference forest

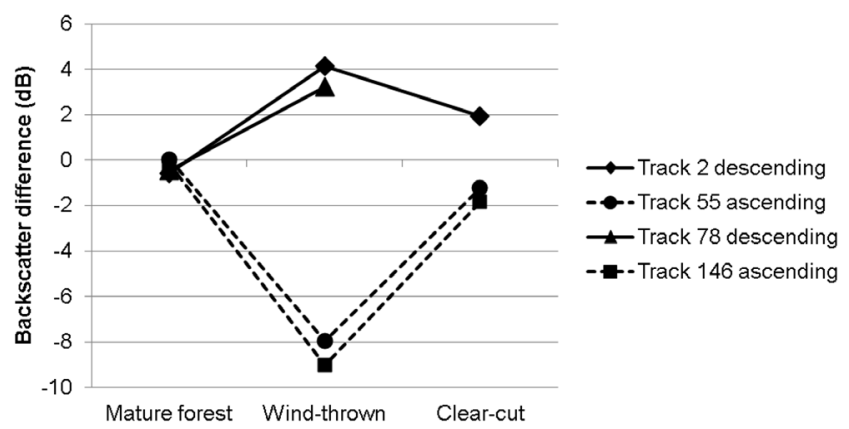

Figure 5. Difference in TerraSAR-X backscatter values $(\mathrm{HH})$ between treated test areas and reference stands. Only areas with shadow or layover are considered. Includes images from both ascending and descending satellite passes. Each point represents an average of all data colledted during each treatment phase.
TerraSAR-X: Descending shadow - reference forest

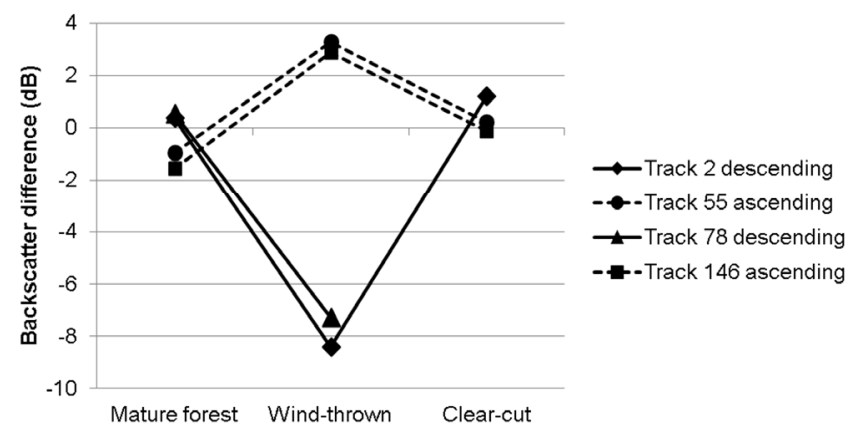

Figure 6. Difference in TerraSAR-X backscatter values $(\mathrm{HH})$ between treated test areas and reference stands. Only areas with shadow or layover are considered. Includes images from both ascending and descending satellite passes. Each point represents an average of all data collected during each treatment phase. 